\title{
Pushing the margins: Research in the Ocean Margin LINK Programme
}

Continental margins are areas of intense exploration interest at the present day, both in NW Europe and across the world. Investigation of the processes involved in shaping margin geology, from crustal geometry to sub-seismic scale reservoir configuration, have contributed to the greater understanding of geological structure in areas of transition from continental crust to oceanic crust.

The Ocean Margin LINK Programme is a research programme co-funded by NERC and industry focusing on the geological evolution of ocean margins. The LINK scheme is the Government's principal mechanism for promoting partnership in research between industry and the academia. The first small grants were allocated in 2000, since which time 14 full projects along with 9 stand-alone studentships have been funded by the Programme, which will end in late 2006. On $16^{\text {th }}$ November 2004 a Workshop was held at DTI in London, giving proponents of projects a chance to summarise research progress and to discuss future collaborations and themes for research.

The Programme has three main themes; deep structure and rifting, sedimentary processes and slope stability, and fluid flow. Projects have covered topics both within and across themes, thereby fitting one of the LINK Programme requirements for multidisciplinary research work. More details are available at the web site (address given below).

The deep structure theme has focussed on characterisation of the nature of the upper lithosphere in the area of margins including those, like the margin NW of the British Isles, associated with volcanic activity. These studies can shed light on aspects of margin evolution, such as heat flow and subsidence, which can have significant implications for hydrocarbon exploration.

The acquired data have included seismic lines across areas of interest to determine deep crustal structure (below the volcanic pile on the NW European margin; Figure 1). Use of low frequency seismic has proved invaluable in identification of the seismic character and thickness of the sediment pile below the highly reflective igneous rocks.

The seismic imaging has been combined with fluid flow modelling of lithospheric extension. This model assumes that extension is not uniform with depth, predicts subsidence but not extension of the upper crust during the early period of continental break up and appear to be consistent with observed data. The integration of predictive models with observations of gravity, heat flow and sediment thickness has proved valuable in clarifying the structure of margins.

Associated with the study of deep structure is analysis of fault activity. Many of these faults are controlled to some extent by pre-existing structures (Figure 2) leading to complexity in the patterns of faulting associated with break up and extension. This 
can be studied on a variety of scales from basin wide to outcrop and the structuration has implications for basin evolution and reservoir properties.

Sedimentological studies have focussed on the characteristics of gravity flows, including the features that relate to separation of flows and sediment distributions within channels. Both outcrop and laboratory studies have provided information on the nature of sediment flows. The combination of experimental modelling of flows and the resulting sediment distribution (Figure 3) with logging of sediment beds at outcrop is central to prediction of the location of reservoir quality sandstones. Study of sidescan sonar images of the sea bed is also of value in examining sediment transport processes. These images (Figure 4) are also invaluable when used in combination with shallow seismic data to assess geohazards on the shelf and slope.

Understanding various aspects of fluid flow within the marginal basins is also important in predicting reservoir quality, trap location and slope stability. The presence of gas hydrate and its implications for causing slope instability under seismic shock are being modelled and the thermal history of the NW UK margin is proving to be a valuable guide to determining the timing of hydrocarbon migration. The characteristics of degraded hydrocarbons are proving to be a more detailed diagnostic tool for determining the origins of the resource. Modelling of fluid flow within deep basins integrates sedimentological and structural data to predict fault seal properties in deep water basins (Figure 5).

Overall the programme has displayed significant value for multidisciplinary work in the area of margins research. The integration of fluid flow, fault geometry and sediment body stacking has had significant implications for prediction of hydrocarbon resources. Modelling of the margins, allied to high quality seismic studies, will help to define depocentre geometries both during and after continental break-up.

The three themes together are building towards an integrated model of ocean margin creation and evolution that provides improved understanding and prediction of resources in hydrocarbon exploration, of slope instability and geohazards and of the new resource that potentially can be provided by hydrate accumulations.

Details of individual projects in the Ocean Margin LINK Programme, including abstracts and presentations, are given at the web site:

http://www.nerc.ac.uk/funding/thematics/oceanmargins/

Dr Alick Leslie

OML Science Co-ordinator

Email: aleslie@bgs.ac.uk

Tel: 01316500315

Fax: 01316684140 
NATURAL

ENVIRONMENT RESEARCH COUNCIL

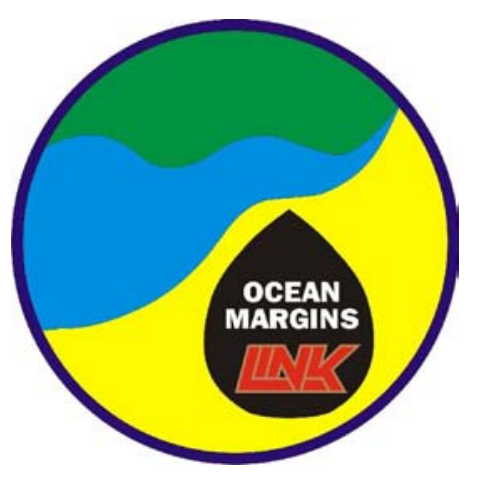

IIT Collaborative

research 


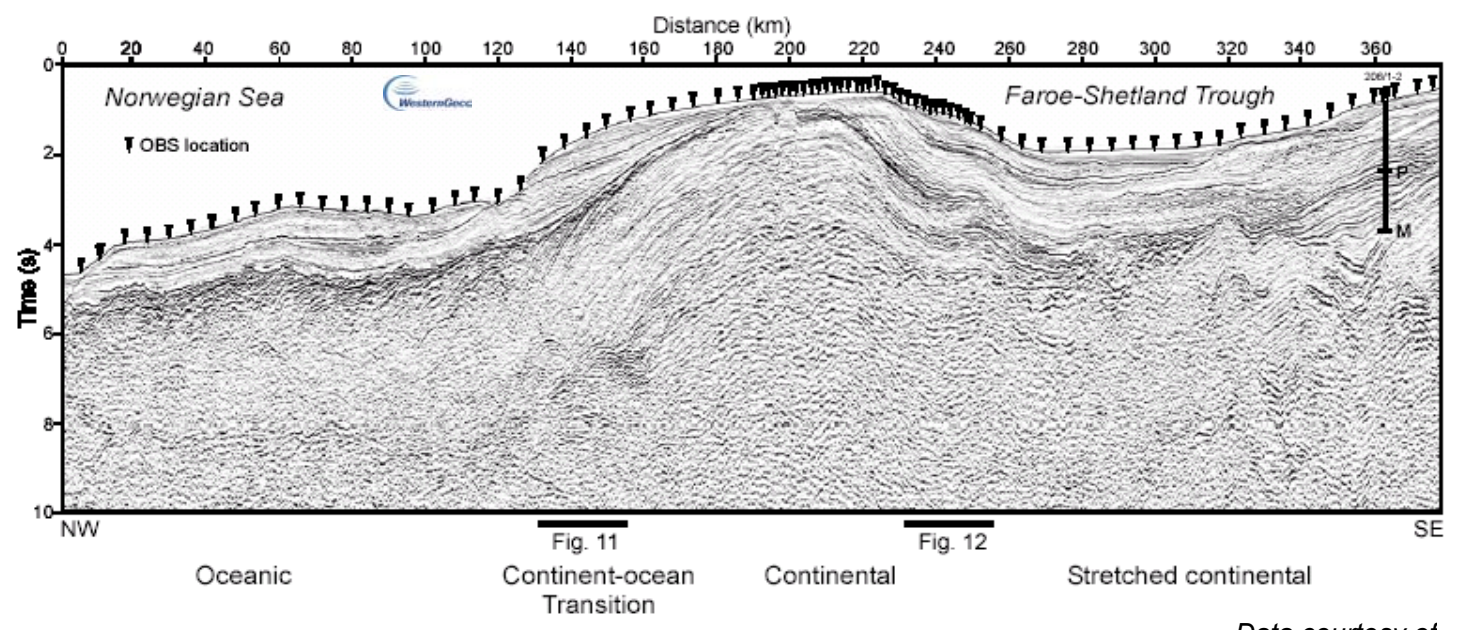

Figure 1. Deep seismic image across the Hatton continent ocean boundary. (White, Christie and the iSIMM Team, 2004). 


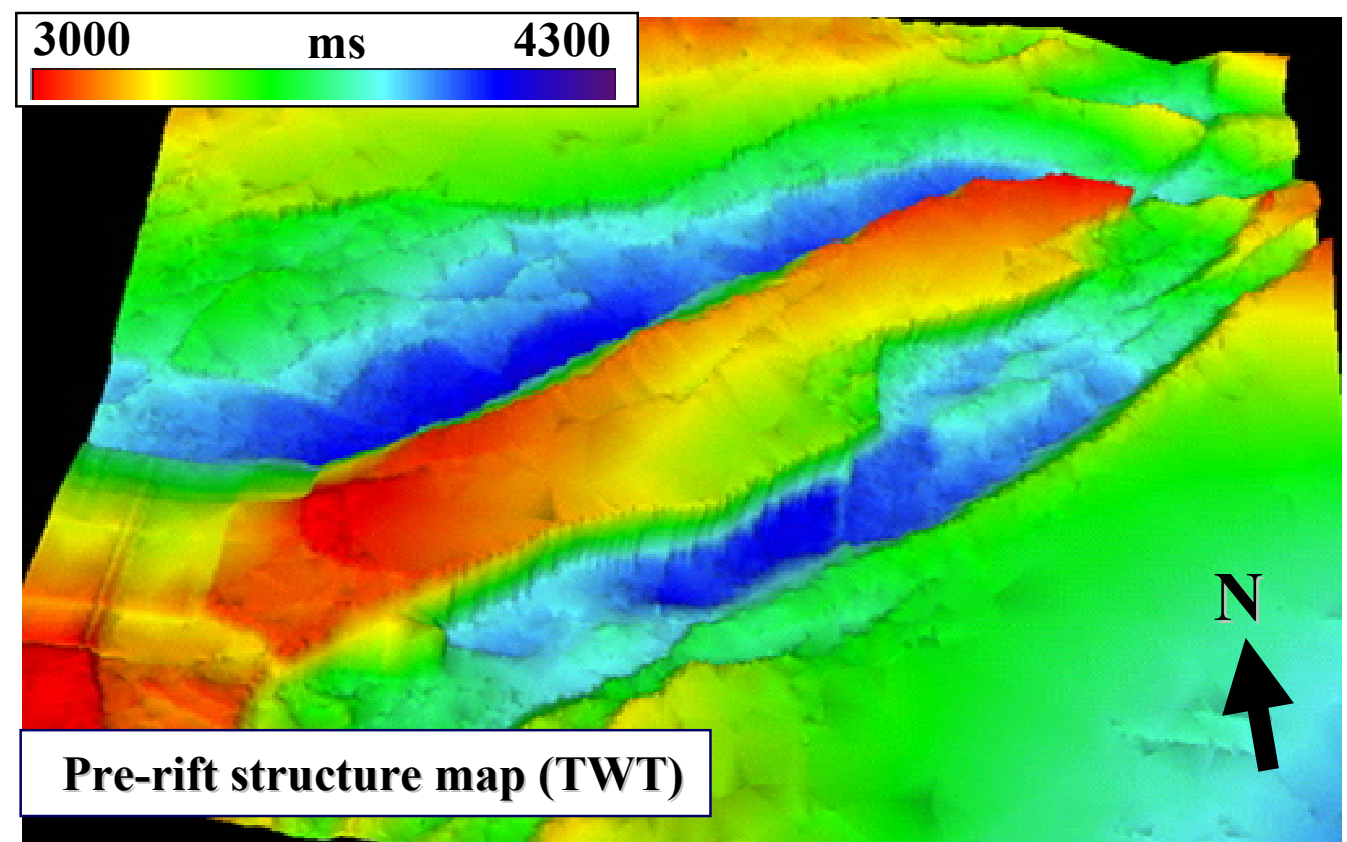

Figure 2. A 3D seismic dataset from the Norwegian Margin with topography on the faulted pre-rift surface. Image courtesy of BP. (Holdsworth et al. 2004). 


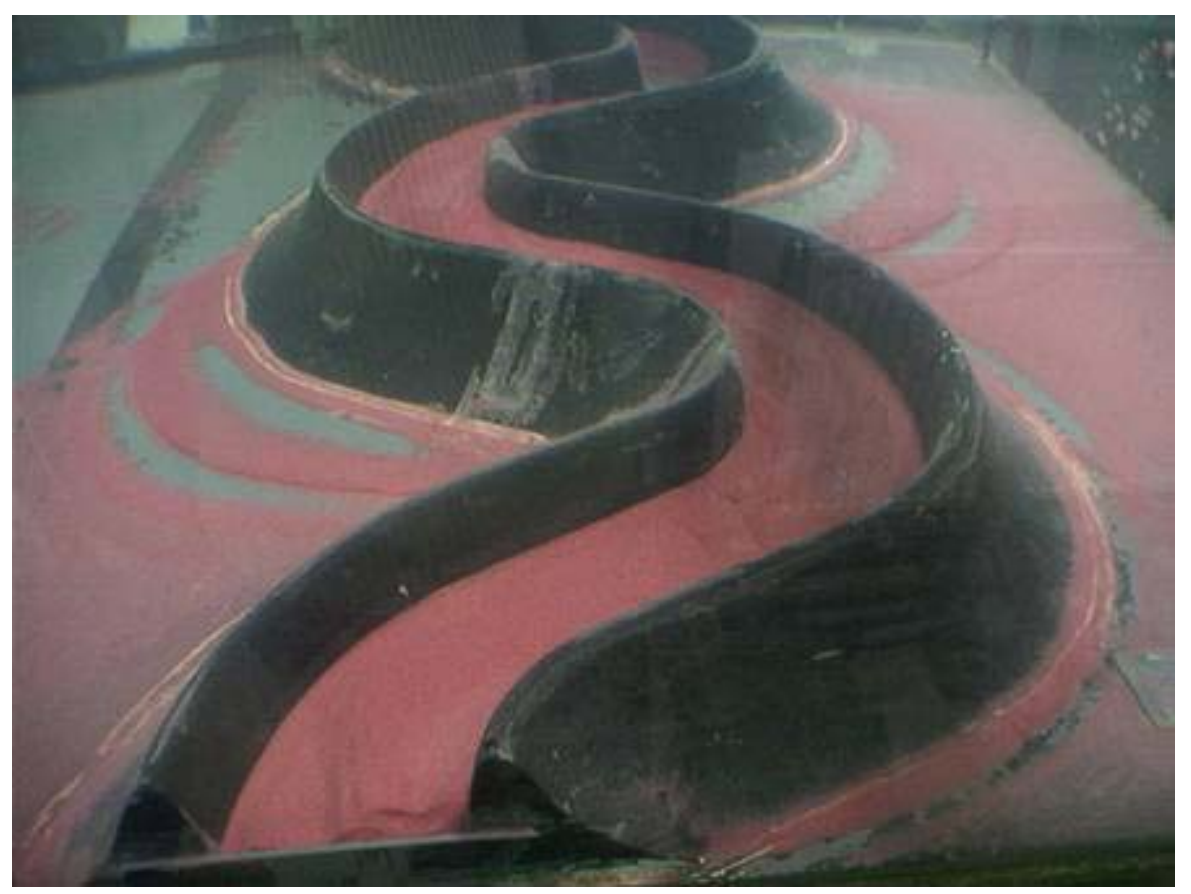

Figure 3. Sediment (red angular plastic grains) both within an experimental sinuous channel and in 'overbank' settings (Amos et al. 2004). The channel is $150 \mathrm{~mm}$ in width, flow towards the camera. 


\section{Sediment/debris slides}

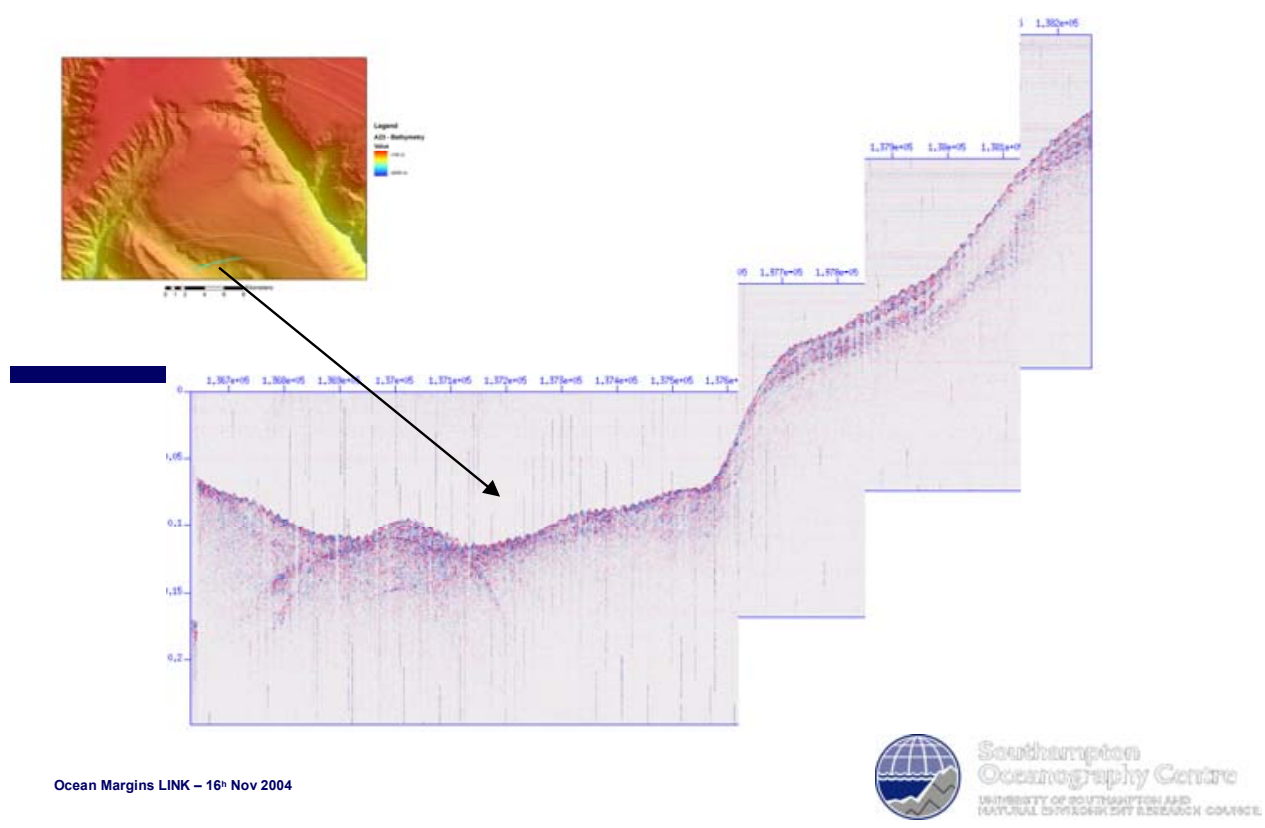

Figure 4. Geohazards including slope failures on the Celtic Margin SW of the UK. (Cunningham et al. 2004). 


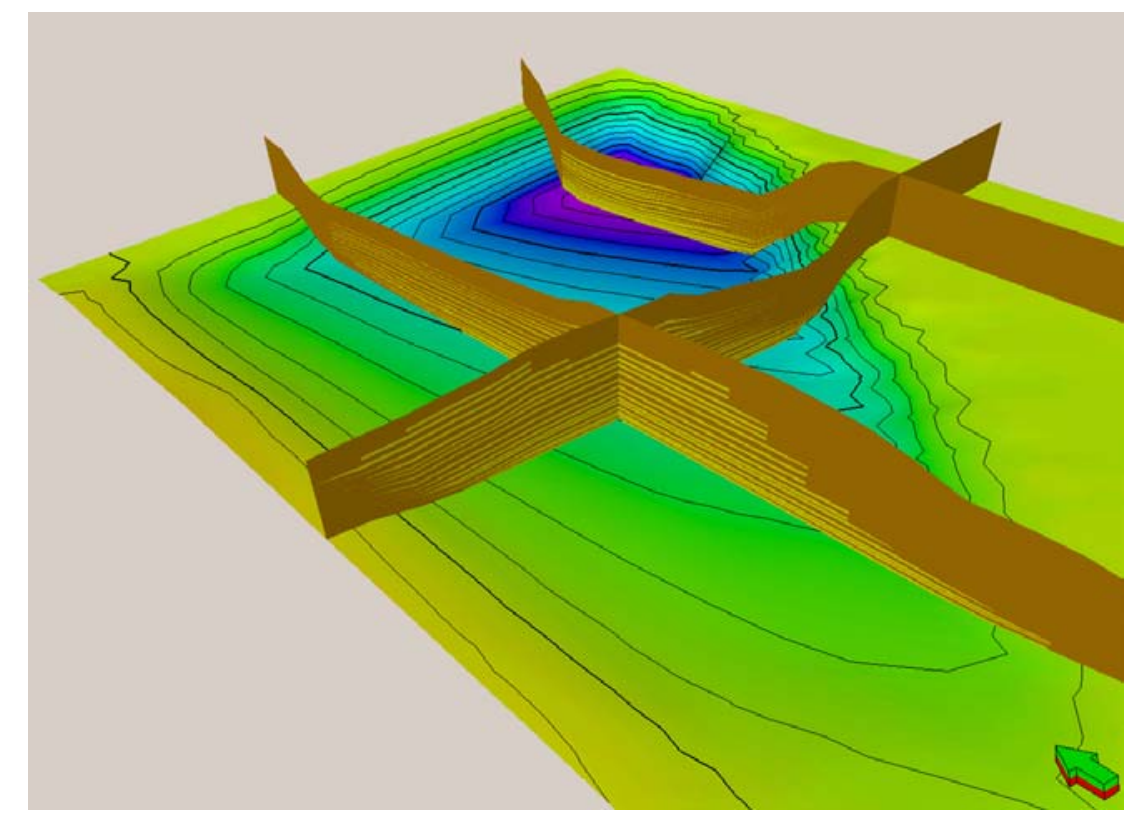

Figure 5. Model of a deep basin containing sand bodies (yellow) within fine grained sediments (brown). Faulting of this sediment package provides the basis for a $3 \mathrm{D}$ model for a faulted turbidite trap. (Knipe et al. 2004)

\section{References}

Amos, K.J., Peakall, J.P., Gupta, S. and Laursen, Y. 2004 Experimental models of gravity current flow in sinuous submarine channels: flow structure and deposit characteristics.

Cunningham, M.J., Parson, L.M. and Masson, D.G. 2004 Slope stability of the Celtic margin (Bay of Biscay).

Holdsworth, R.E., McCaffrey, K.J.W., Imber, J., Wilson, R.W., Jones, R.R., England, R.W., Gjeldvik, G., Dore, A.G and Freeman, S. 2004 Reactivation and the structural evolution of ocean margins: an onshore-offshore study of the Norwegian margin.

Knipe, R.J., McCaffrey, W.D., Baas, J.H., Bradbury, W., Freeman, S., Harris, S.D. and Lewis, G. 2004 Fault seal processes and trap development in deep marine reservoirs.

Kusznir, N.J. and the iSIMM team. 2004 A kinematic fluid-flow model of sea-floor spreading initiation and rifted continental margin formation 